\title{
Couples' attitude toward husband attendance during childbirth
}

\section{Safaa Rashad Mahmoud, Safaa Ibrahim Ahmed \& Nabila Taha}

Community Health Nursing, Faculty of Nursing, Assiut University, Egypt. Obstetrics \& Gynecological Health Nursing, Faculty of Nursing, Sohag University, Egypt. Obstetrics \& Gynecological Nursing, Faculty of Nursing, Assiut University, Egypt.

\begin{abstract}
Childbirth is a turning point in life. The presence of the husband in the delivery room can provide emotional support for the mother; establish an earlier relationship between a father and his infant. Aim to identify the couples' attitude toward husband attendance during childbirth. Descriptive design was used in this study. Convenient sample of 270 couples were recruited for this study. The Settings were 4 villages from Assiut \& Sohag governorates (two from each). Tools of data collection were interview questionnaire which include personal data for both husband \& wife, and the couples' attitude scale which includes 27 statements with five points Likert' scale. Results More than onethird of wives and their husbands have had university education; half of the studied wives were employee. There was positive attitude among both couples and there was positive correlation between husband and wife attitude. The study concluded that the majority of couples believed that attendance of husband during childbirth provide mother with emotional support, and strengthens the couple's relationship. Recommendations facilities, physicians and nurses should allow and encourage husband to attend child birth, also further researches about the husband's presence and its effect on perinatal outcomes is highly recommended.
\end{abstract}

\section{Keywords: Couples, Attitude, attendance \& Childbirth}

\section{Introduction}

One of the most stressful events in a woman's life is childbirth; continuous support during labor has been found beneficial in reducing maternal distress, (Shahshahan et al., 2014). A major factor that influences the mother's perception of a positive experience is how supported she feels throughout childbirth (Hodnett et al., 2011).

A new birth culture that focused on family-centered approaches to care had developed in western society by the 1970's. Fathers were not only allowed to attend the birth of their children, but were encouraged to assume active roles in supporting their partner. Men were encouraged to attend prenatal classes where they learnt about techniques to help their partner during labor (Blackshaw, 2009).

A husband's support during childbirth is vital to a parturient woman's emotional well-being. Evidence suggests that this type of support enables a woman to feel more in control during labor by reducing maternal anxiety during childbirth, (Sapkota et al., 2011).

The presence and active involvement of fathers during labor as well as delivery has been described as a 'recent phenomenon', moving from unusual to normative and universally accepted in western societies. However, this transition has not gone unopposed (Blackshaw, 2009).

A number of studies have revealed that the partner's support during labor and childbirth contributed to a more positive birth experience, shorter duration labor, and a smoother transition into parenthood. (Sapkota et al., 2012., Kainz et al., 2010, Price et al., 2007, \& Somers-Smith, 1999). Husbands help to alleviate maternal stress and fears, promote strength, endurance, comfort and security, help distract from the pain, and in general, contribute to a more satisfactory birth experience (Kainz et al., 2010).

Men can affect pregnancy and childbirth through responding to complications, seeking medical help, paying for transport, and allocating household resources. However, the role of husbands in maternal health is often overlooked and neglected. (Mullany et al, $2007 \&$ Furuta \& Salway, 2006).

Research has shown that the fathers' presence at birth helps to strengthen family togetherness, improve the couple's relationship and helps him bond with the baby. Furthermore, it has been largely reported that the presence of the father at childbirth is integral for his transition into parenthood. When his first child is born, it is a significant moment for the acceptance of fatherhood for him, the moment he actually becomes a father ( Plantin et al., 2011, Kainz et al., 2010; Pestvenidze \& Bohrer, 2007, \&Cooper, 2005).

Giving birth, particularly for the first time, can be a stressful event for some women, as they anticipate the unknown challenges that face them. Many experience fear, pain and anxiety that can be further exacerbated by an unfamiliar hospital birth setting. Moreover, if a woman remains in a stressful state, 
this can have potentially adverse effects on the progress of labor. It is no wonder then that having a close, supportive companion nearby can be beneficial for a woman in this position (Staessen, 2005).

Recently there has been an increasing trend towards male partners attending childbirth in postindustrialized countries. However, in some countries, due to limited cultural acceptability and outdated delivery practices, fathers are not welcomed or even allowed into the delivery room. World experience postulates that fathers' involvement in childbirth has many advantages. (Lewis et al., 2015).

Most cultures, especially in Africa, regard pregnancy and delivery as a female domain; therefore, men are often not expected to be present during delivery (Theuring et al., 2009). Previous studies have highlighted significant barriers to male participation as pregnancy and childbirth are often perceived as a woman's realm. Men's involvement is culturally discouraged as many of the important barriers for husbands, like social pressure, lack of knowledge and spousal communication are gender related; men's focus was on economic activity which was more important for them to concentrate on. Men reported they were too busy for such tasks, (Lewis et al., 2015). Birth is the moment that fathers ascribe as the beginning of fatherhood. However, through their lack of knowledge and perceived control, they struggle to find a role there, (Heather, et al., 2011).

\section{Significance of the study}

Despite documented advantages of fathers' involvement in childbirth, it still remains challenging to implement; especially where the concept is still new within the cultural values and norms of Arab \& Islamic societies. Husband attendance during child birth is uncommon in our communities, since in Egypt has no tradition of the husband's presence in the delivery room, also presence of husband is not a routine or even allowed into the delivery room; Egyptians has little experience of this practice. Also, one study conducted at Assiut city by El-Maghrabi \& Mohamed (2012), recommended further researches about the husband's attitude toward his presence during childbirth. Therefore, this study was carried out to identify the couples' attitude toward husband attendance during childbirth.

\section{Study questions}

- Is there a positive couples' attitude toward attendance of a husband during delivery?

- Is there a correlation between wife's attitude and husband attitude?

\section{Aim of the study}

This study aimed to identify the couples' attitude toward husband attendance during childbirth

\section{Subjects \& Methods}

\section{Study design}

A descriptive design was used in this study.

Setting

The study was conducted at four villages that were chosen by simple random sample two from Assiut governorate called (Alzawia \& Mosha villages), also two from Sohag governorate called (Alshaheed \& Alsawamaa villages and its hamlets).

Subjects

A convenient sample of 270 couples was recruited for this study. There were no inclusion criteria, apartScoring system

Each scoring response is classified one to five degrees. 1 degree is assigned for complete disagreement, 2 degrees for disagreement, 3 degrees for neutral, and 4 degrees for agreement, 5 degrees for complete agreement. Total scores of scale ranged between 27 and 135. Cumulative scores from 81-135 were considered as 'positive attitudes', from 68-80 were 'neutral attitudes'. And less than 68 were considered as 'negative attitudes.

\section{Content Validity \& Reliability of the tool}

The tool was validated by the original author, which the content validity was confirmed by faculty staff with a coefficient of $0.9 \%$. The reliability was confirmed by Cronbach's alpha with a reliability coefficient of $0.9 \%$. Also, the investigators of previous study, (El-Maghrabi \& Mohamed 2012) on the woman's attitude towards the presence of husband in the labor room during childbirth, which conducted at Assiut, translated the scale from English to Arabic language, they revalidate the tool by a jury of expertise from community health nursing, Obstetric and gynecological nursing and Psychiatric nursing, to test its contents' validity; (five of experts) to assess the content and face validity of the tool for Egyptian culture.

\section{Administrative approval}

The necessary official permission was obtained from the Dean of Faculty of Nursing, Assiut University \& from the general directorate of health \& population affairs to proceed with the study.

Pilot study

A Pilot study was conducted on $10 \%$ of the subjects, to assess the clarity of the tools and to estimate the time required for filling the tools. Those subjects were included in the study. 


\section{Field work}

As a data base from rural health unit affiliated to Ministry of Health and Population for the previous mentioned villages, address of pregnant woman was taken, total coverage of all pregnant women and their husbands were done through home visits. The study started from November 2014-to the end of June 2015. The investigators accompanied with the worker of the rural health unit or the Raeda Refea go to the pregnant woman's home, introduced themselves to the woman and her husband, and then briefly explained the nature of the study. The investigators introduced the attitude -testing expressions scale, and the filling of the interview questionnaire took 40-50 minutes for each couple; (the interview questionnaire $\&$ scale were filled by the investigators) the data were collected two days/week, and 3-5 couples/ day were interviewed.

\section{Ethical consideration}

A formal consent was obtained orally from couples before being involved in the study. The nature and purpose of the study were explained. The investigators informed the couples that there is no risk or cost for participation, and the participation is voluntary. Also, the couples were assured that the confidentiality of information will be secured and anonymity of each subject will be maintained.

\section{Limitation of the study}

- Encounters the absence of the husband during the visit, a difficulty to the investigators to go back to the same home another time/s.

\section{Statistical analysis}

Collected data were coded, analyzed and tabulated using SPSS version 19 (Statistical Package for Social Science). Data were presented as number, percentage, mean, standard deviation. Chi-square test was used to compare between qualitative variables. Spearman correlation was done to measure correlation between quantitative variables. P-value considered statistically significant when $\mathrm{P}<0.05$. 


\section{Results}

Table (1): distribution of the study couples according to their personal characteristics $(n=270)$.

\begin{tabular}{|c|c|c|}
\hline Items & No. & $\%$ \\
\hline \multicolumn{3}{|l|}{ Husband age } \\
\hline$<30$ years & 70 & 25.9 \\
\hline $30-<35$ years & 70 & 25.9 \\
\hline $35-<40$ years & 61 & 22.6 \\
\hline$\geq 40$ years & 69 & 25.6 \\
\hline Mean \pm SD (Range) & \multicolumn{2}{|c|}{$34.34 \pm 6.54(19.0-50.0)$} \\
\hline \multicolumn{3}{|l|}{ Husband education } \\
\hline University & 103 & 38.1 \\
\hline Secondary & 131 & 48.5 \\
\hline Basic education & 14 & 5.2 \\
\hline Illiterate & 22 & 8.1 \\
\hline \multicolumn{3}{|l|}{ Husband occupation } \\
\hline Working & 252 & 93.3 \\
\hline Not working & 18 & 6.7 \\
\hline \multicolumn{3}{|l|}{ No. of pregnancies } \\
\hline One & 83 & 30.7 \\
\hline Two & 75 & 27.8 \\
\hline Three & 65 & 24.1 \\
\hline More than three & 47 & 17.4 \\
\hline Mean \pm SD (Range) & \multicolumn{2}{|c|}{$2.35 \pm 1.22(1.0-5.0)$} \\
\hline \multicolumn{3}{|l|}{ Wife age } \\
\hline$<25$ years & 66 & 24.4 \\
\hline $25-<30$ years & 101 & 37.4 \\
\hline $30-<35$ years & 54 & 20.0 \\
\hline$\geq 35$ years & 49 & 18.1 \\
\hline Mean \pm SD (Range) & \multicolumn{2}{|c|}{$(28.49 \pm 5.82(17.0-40.0)$} \\
\hline \multicolumn{3}{|l|}{ Wife education } \\
\hline University & 100 & 37.0 \\
\hline Secondary & 104 & 38.5 \\
\hline Basic education & 35 & 13.0 \\
\hline Illiterate & 31 & 11.5 \\
\hline \multicolumn{3}{|l|}{ Wife occupation } \\
\hline Working & 139 & 51.5 \\
\hline Housewife & 131 & 48.5 \\
\hline
\end{tabular}

N.B: None of participated husband had attend previous child birth 
Table (2) Mean score of couples' attitude scale among the studied couples $(n=270)$.

\begin{tabular}{|l|c|c|}
\hline \multicolumn{1}{|c|}{ Statements } & Husband & Wife \\
\cline { 2 - 3 } & Mean \pm SD & Mean \pm SD \\
\hline $\begin{array}{l}\text { 1. Is pleasurable since observing childbirth is one of the most } \\
\text { important moments in life }\end{array}$ & $3.11 \pm 1.37$ & $3.04 \pm 1.24$ \\
\hline 2. Provides emotional support to the mother. & $3.76 \pm 1.08$ & $4.00 \pm 0.92$ \\
\hline $\begin{array}{l}\text { 3. Provides the mother the opportunity to express her problems to a } \\
\text { familiar person }\end{array}$ & $3.36 \pm 1.10$ & $3.55 \pm 1.05$ \\
\hline 4. Increases the mother's self-confidence & $3.80 \pm 1.07$ & $3.95 \pm 0.97$ \\
\hline 5. Increases the husband's sympathy and gratitude towards his wife. & $3.86 \pm 1.03$ & $4.08 \pm 0.85$ \\
\hline 6. Allows the husband to share the pain of delivery with his wife. & $3.38 \pm 1.15$ & $3.61 \pm 0.99$ \\
\hline 7. Prepares the husband to accept his paternal responsibility & $3.79 \pm 1.00$ & $3.98 \pm 0.87$ \\
\hline 8. Has positive effects on the husband's & $3.30 \pm 1.05$ & $3.52 \pm 0.94$ \\
\hline 9. Strengthens the couple's relationship & $3.79 \pm 0.97$ & $4.01 \pm 0.88$ \\
\hline 10. Creates a feeling of pride in the husband & $3.47 \pm 0.97$ & $3.45 \pm 0.88$ \\
\hline 11. Decreases the mother's anxiety & $3.77 \pm 1.03$ & $3.74 \pm 0.94$ \\
\hline 12. Helps the mother bears labor pain & $3.70 \pm 1.10$ & $3.62 \pm 1.06$ \\
\hline 13. Has a positive effect on father-child relationship & $3.78 \pm 1.04$ & $3.91 \pm 0.90$ \\
\hline 14. Is not helpful to the mother & $3.55 \pm 1.01$ & $3.66 \pm 0.99$ \\
\hline 15. Increases the husband's self-confidence & $3.25 \pm 1.04$ & $3.34 \pm 1.00$ \\
\hline 16. May lead to psychological disorders in the husband & $3.27 \pm 1.14$ & $3.25 \pm 1.00$ \\
\hline 17. Transfers the husband's anxiety to the mother & $3.23 \pm 1.12$ & $3.06 \pm 0.99$ \\
\hline 18. Is not a good idea since the delivery room is not suitable for men & $2.70 \pm 1.25$ & $2.87 \pm 1.24$ \\
\hline 19. Is calming for the husband & $3.30 \pm 1.12$ & $3.22 \pm 1.04$ \\
\hline 20. Is calming for the mother & $3.57 \pm 0.99$ & $3.63 \pm 1.04$ \\
\hline 21. Is unpleasant for the mother & $3.33 \pm 1.12$ & $3.53 \pm 1.14$ \\
\hline 22-Is the husband's duty & $3.43 \pm 1.11$ & $3.44 \pm 1.09$ \\
\hline 23-Decreases the husband's anxiety & $3.43 \pm 1.10$ & $3.40 \pm 0.98$ \\
\hline 24. Is not tolerable for the husband & $3.03 \pm 1.15$ & $3.11 \pm 1.14$ \\
\hline 25. Is against Egypt culture & $2.93 \pm 1.30$ & $3.01 \pm 1.21$ \\
\hline 26. Is frightening in the case of a complicated delivery & $2.76 \pm 1.19$ & $2.87 \pm 1.13$ \\
\hline 27. Is frightening for the husband & $2.90 \pm 1.26$ & $3.04 \pm 1.15$ \\
\hline
\end{tabular}

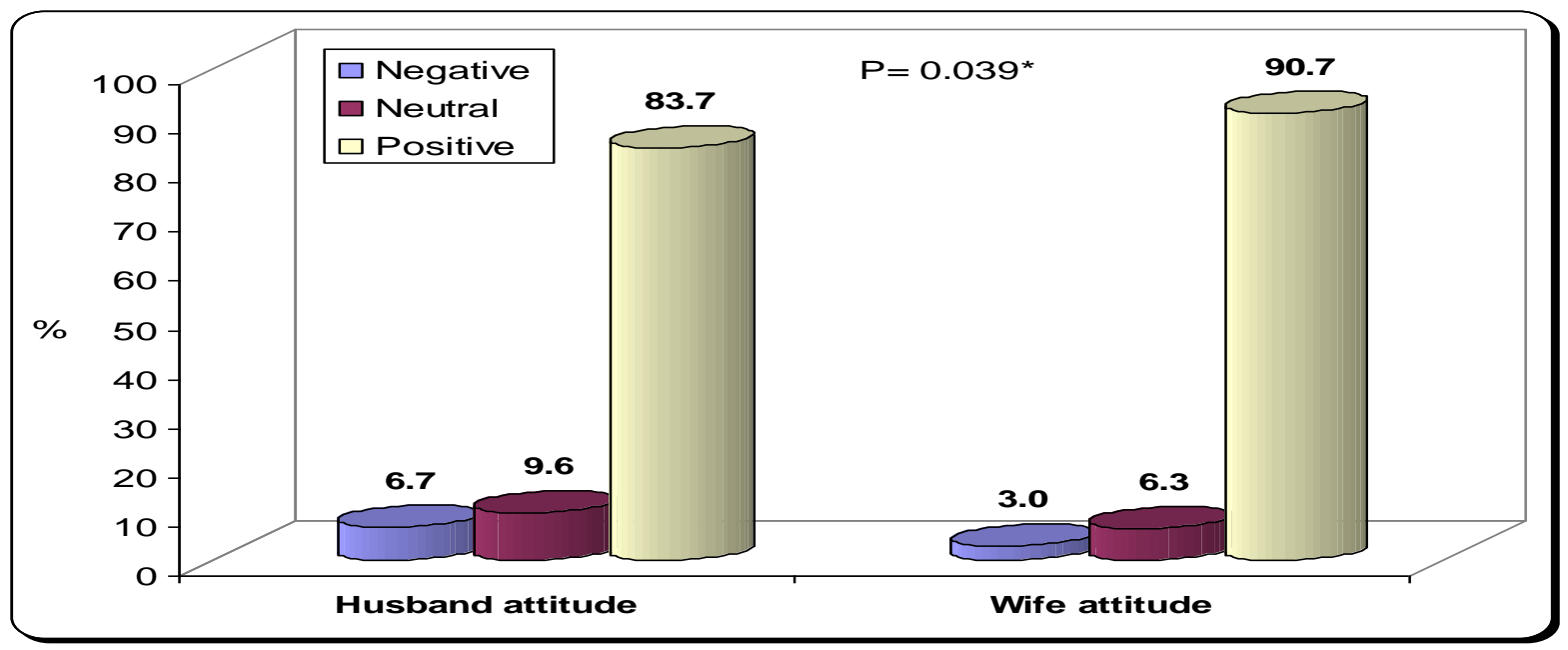

Figure (1): Couples' attitude toward husband attendance during child birth. 


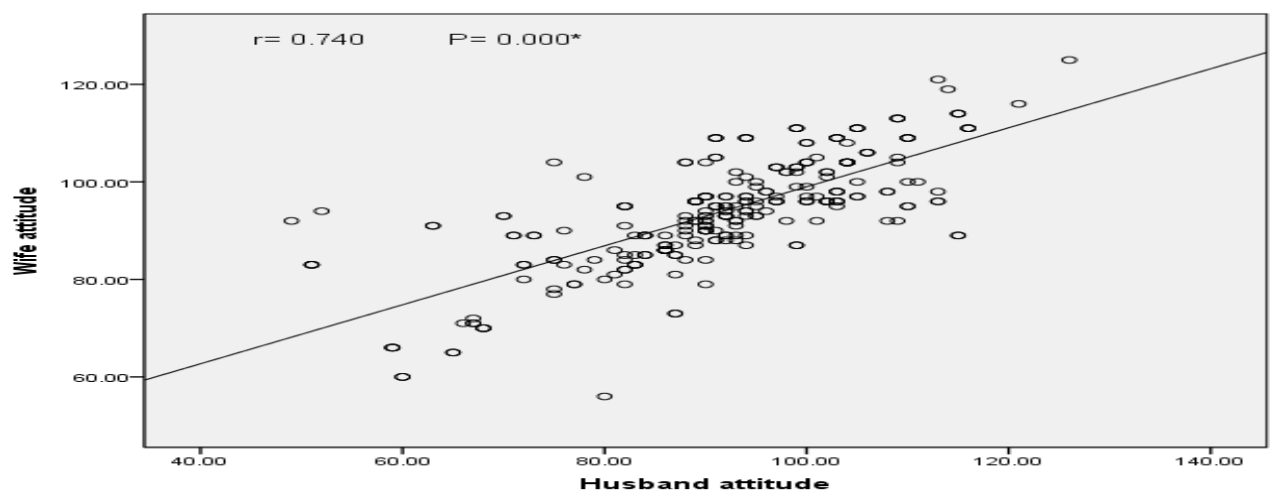

Figure (2): Correlation between husband and wife attitude

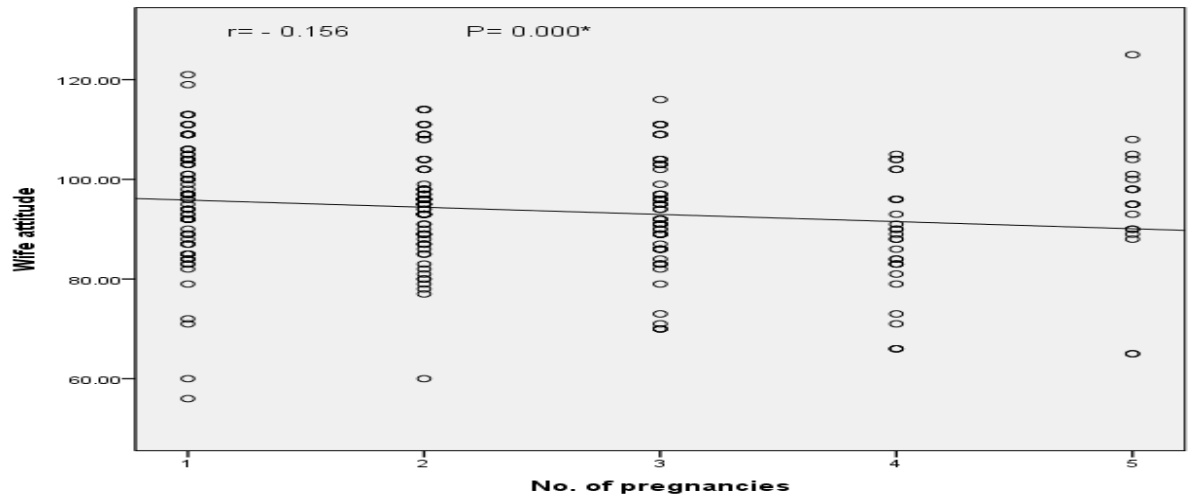

Figure (3): Correlation between number of pregnancy and wife attitude

Table (3): relationship between husbands' attitude and their personal characteristics.

\begin{tabular}{|c|c|c|c|c|c|c|c|}
\hline \multirow{3}{*}{ Items } & \multicolumn{6}{|c|}{ Husband attitude } & \multirow{3}{*}{$\begin{array}{c}\left(\mathrm{X}^{2}\right) \\
\text { P-value }\end{array}$} \\
\hline & \multicolumn{2}{|c|}{$\begin{array}{c}\text { Negative } \\
(n=18)\end{array}$} & \multicolumn{2}{|c|}{$\begin{array}{c}\text { Neutral } \\
(n=26)\end{array}$} & \multicolumn{2}{|c|}{$\begin{array}{l}\text { Positive } \\
(n=226)\end{array}$} & \\
\hline & No. & $\%$ & No. & $\%$ & No. & $\%$ & \\
\hline \multicolumn{7}{|l|}{ Husband age } & \multirow{5}{*}{$\begin{array}{c}(10.96) \\
0.090\end{array}$} \\
\hline$<30$ years & 4 & 5.7 & 7 & 10.0 & 59 & 84.3 & \\
\hline $30-<35$ years & 1 & 1.4 & 5 & 7.1 & 64 & 91.4 & \\
\hline $35-<40$ years & 9 & 14.8 & 7 & 11.5 & 45 & 73.8 & \\
\hline$\geq 40$ years & 4 & 5.8 & 7 & 10.1 & 58 & 84.1 & \\
\hline \multicolumn{7}{|l|}{ Husband education } & \multirow{5}{*}{$\begin{array}{l}(8.81) \\
0.185\end{array}$} \\
\hline University & 8 & 7.8 & 4 & 3.9 & 91 & 88.3 & \\
\hline Secondary & 9 & 6.9 & 17 & 13.0 & 105 & 80.2 & \\
\hline Basic education & 0 & 0.0 & 1 & 7.1 & 13 & 92.9 & \\
\hline Illiterate & 1 & 4.5 & 4 & 18.2 & 17 & 77.3 & \\
\hline \multicolumn{7}{|c|}{ Husband occupation } & \multirow{3}{*}{$\begin{array}{l}(3.76) \\
0.153\end{array}$} \\
\hline Working & 18 & 7.1 & 26 & 10.3 & 208 & 82.5 & \\
\hline Not working & 0 & 0.0 & 0 & 0.0 & 18 & 100.0 & \\
\hline
\end{tabular}


Table (4): relationship between wives' attitude and their personal characteristics.

\begin{tabular}{|c|c|c|c|c|c|c|c|}
\hline \multirow{3}{*}{ Items } & \multicolumn{6}{|c|}{ Wife attitude } & \multirow{3}{*}{$\begin{array}{c}\left(X^{2}\right) \\
\text { P-value }\end{array}$} \\
\hline & \multicolumn{2}{|c|}{$\begin{array}{l}\text { Negative } \\
(n=8)\end{array}$} & \multicolumn{2}{|c|}{$\begin{array}{c}\text { Neutral } \\
(n=17)\end{array}$} & \multicolumn{2}{|c|}{$\begin{array}{l}\text { Positive } \\
(n=245)\end{array}$} & \\
\hline & No. & $\%$ & No. & $\%$ & No. & $\%$ & \\
\hline \multicolumn{7}{|l|}{ Wife age } & \multirow{5}{*}{$\begin{array}{c}(10.47) \\
0.106\end{array}$} \\
\hline$<25$ years & 1 & 1.5 & 5 & 7.6 & 60 & 90.9 & \\
\hline $25-<30$ years & 2 & 2.0 & 7 & 6.9 & 92 & 91.1 & \\
\hline $30-<35$ years & 5 & 9.3 & 3 & 5.6 & 46 & 85.2 & \\
\hline$\geq 35$ years & 0 & 0.0 & 2 & 4.1 & 47 & 95.9 & \\
\hline \multicolumn{7}{|l|}{ Wife education } & \multirow{5}{*}{$\begin{array}{l}(7.73) \\
0.258\end{array}$} \\
\hline University & 5 & 5.0 & 4 & 4.0 & 91 & 91.0 & \\
\hline Secondary & 2 & 1.9 & 5 & 4.8 & 97 & 93.3 & \\
\hline Basic education & 1 & 2.9 & 4 & 11.4 & 30 & 85.7 & \\
\hline Illiterate & 0 & 0.0 & 4 & 12.9 & 27 & 87.1 & \\
\hline \multicolumn{7}{|l|}{ Wife occupation } & \multirow{3}{*}{$\begin{array}{l}(2.23) \\
0.328\end{array}$} \\
\hline Working & 5 & 3.6 & 6 & 4.3 & 128 & 92.1 & \\
\hline Not working & 3 & 2.3 & 11 & 8.4 & 117 & 89.3 & \\
\hline \multicolumn{7}{|l|}{ No. of pregnancies } & \multirow{5}{*}{$\begin{array}{l}(14.30) \\
0.026^{*}\end{array}$} \\
\hline One & 2 & 2.4 & 3 & 3.6 & 78 & 94.0 & \\
\hline Two & 1 & 1.3 & 5 & 6.7 & 69 & 92.0 & \\
\hline Three & 0 & 0.0 & 6 & 9.2 & 59 & 90.8 & \\
\hline More than three & 5 & 10.6 & 3 & 6.4 & 39 & 83.0 & \\
\hline
\end{tabular}

Table (1): showed that the mean age of the wives and their husbands was $(28.49 \pm 5.82 \& 34.34 \pm 6.54$ years), respectively. More than one-third of wives and their husbands have had university education $(37.0 \%$ \& $38.1 \%)$ respectively. The not working husbands were $(6.7 \%)$, while slightly more than half of the studied wives was working $(51.5 \%)$, around one-third of them was pregnant for the first time $(30.7 \%)$, and more than one-quarter of them was pregnant for the second time $(27.8 \%)$. The mean number of pregnancies among study wives is $(2.35 \pm$ 1.22).

Table (2): Represented the mean attitude scores for the individual items on the questionnaire. It was found that both wives and husbands were agreeing for almost all positive items of the scale, high mean scores were observed on items no. 2; Provides emotional support to the mother $(3.76 \pm 1.08 \& 4.00$ $\pm 0.92)$, no.4; Increases the mother's self-confidence $(3.80 \pm 1.07 \& 3.95 \pm 0.97)$, no. 5; Increases the husband's sympathy and gratitude towards his wife $(3.86 \pm 1.03 \& 4.08 \pm 0.85), \&$ no.9; Strengthens the couple's relationship $(3.79 \pm 0.97 \& 4.01 \pm 0.88)$. They have neutral responses for negative statements, such as item no. 18; Is not a good idea since the delivery room is not suitable for men $(2.70 \pm 1.25 \&$ $2.87 \pm 1.24) \&$ item no. 26 ; Is frightening in the case of a complicated delivery $(2.76 \pm 1.19 \& 2.87 \pm$ 1.13).
Figure (1): illustrated that there was positive attitude among both wife and husband toward husband attendance during child birth. The differences were statistically significant. $(\mathrm{P}=0.039)$.

Figure (2): demonstrated that there was a positive correlation between husband and wife attitude ( $r=$ $0.740)$.

Figure (3): demonstrated that there was a negative correlation between number of pregnancy and wife attitude $(\mathrm{r}=-0.156)$.

Table (3): Clarified that there were no statistically significant differences between husbands' attitude and their personal characteristics for all items regarding age, education, \& occupation.

Table (4): Illustrated that there are statistically significant differences between wives' attitude and the number of pregnancy $(\mathrm{P}=0.026)$. While there are no statistically significant differences between their attitude and personal characteristics for all items regarding age, education, \& occupation.

\section{Discussion}

Various studies have investigated the presence of the husband during labor, but this practice is still uncommon in some Islamic countries. In Western Society, there is clear understanding of the greater effect of a husband's attendance during childbirth which enables his wife to feel more secure and reduced the expected anxiety and pain of the labor 
process (El-Maghrabi, \& Mohamed, 2012, Larkin, et al., 2009, \& Staessen, 2005).

There are wide cultural variations worldwide pertaining to childbirth and male involvement. Several studies explore views and experiences of men during childbirth and reported a wide range of experiences that include improvements in the couple's positive attitude towards the birthing process, enhanced father-baby attachment, and father's increased participation in early caretaking activities, Pride related to fatherhood, increased respect for women and improved partners' relationships were reported (Adeniran, et al., 2015, Abusha, 2014, \& Shahshahan et al., 2014).

The results of current study revealed the majority of couples have had positive attitude toward attendance of husband during childbirth, and their attitudes were significantly correlated. This finding was in agreement with the study of Kwambai, et-al., (2013) who found that the Kenyan men were positive in their views of delivery care. Also, a study done in Assiut to investigate the woman's attitude toward presence of husbands in labor room during childbirth by ElMaghrabi, \& Mohamed, (2012), reported that nearly two thirds of women in their study had positive attitudes. Another study in Islamic Republic of Iran, by Nejad, (2005), found that almost all couples had positive attitudes with significant correlation. On the other hand, the result of current study was disagreement with Bakhta \& Lee (2010), who studied A survey of Russian women regarding the presence of a companion during labor they found that more than two thirds of the studied subjects declined to have a partner present during labor. This positive attitude of the majority of participants in the current study reflects their awareness by the importance \& positive effects of the presence of husband during childbirth. Despite all of them were from rural areas in Upper Egypt but large percent of them were had secondary \& university education plus positive attitudes. Media might have had a role in improving couples' attitudes. Most of participated couples reported the willing of husband attendance during child birth, but physicians and midwife refuse, husbands just wait out.

The present study demonstrated that highest attitude main scores were obtained from both couples regarding item of Provides emotional support to the mother \& strengthens the couple's relationship. The same results were in the study of El-Maghrabi \& Mohamed (2012), who found the items of providing emotional support and strength the couple relationship reported highest scores. Kainz et al., (2010), also found that the partners helped the women feel calm which gave her energy to fight through the labor. Also, Somers-Smith (1999), found that the partners acted as a morale booster that increased the women's confidence and motivation to continue. The present study results are also in agreement with Bondas-Salonen's (1998), who finish qualitative study of 40 women's experiences of their partner's attendance at childbirth, he found that the partner's presence offered a sense of comfort by simply knowing that their partner was there if they needed them. This reassured the women that they were not alone. The women expressed the importance of having their partners there, not necessarily to do anything other than be present. The research has shown that having someone constantly available was very important to the women. Other study done in Russia reported that Many Russian women viewed childbirth as a medical process that should not involve social interaction, (Bakhta \& Lee, 2010). These differences can be explained a wide range of cultural differences, in attitudes \& in childbirth practices.

The finding of current study can be explained by the need of woman for security, decrease feeling of loneliness, decrease stress level, \& the need for emotional support during childbirth.

The present study revealed that; high attitude means scores among both couples regarding items of Increases the husband's sympathy and gratitude towards his wife, allows the husband to share the pain of delivery with his wife, prepares the husband to accept his paternal responsibility, has positive effects on the husband's, \& creates a feeling of pride in the husband. These findings were in agreement with Kainz et al., (2010), \& Bondas-Salonen (1998), who found that no one could replace the father in the sharing of the experience, even though others were able to alleviate suffering of woman. The women in these studies felt it was important for their partner to share in the joy and the suffering of the birth, and considered labor an act of teamwork that they managed well together. This offered a sense of pride, and helped them feel closer. Some men also report an increased respect for their wives and further strengthening the couples bond.

Regarding the items of strengthens the couple's relationship, \& has a positive effect on father-child relationship, the current study represented that high mean scores are obtained from both wives and husbands. These finding was in the same line with the study of (Pestvenidze \& Bohrer, 2007), who found that the fathers' presence at birth helps to strengthen family togetherness, improve the couple's relationship and helps him bond with the baby. Furthermore, another two studies have been largely reported that the presence of the father at childbirth is integral for his transition into parenthood (Plantin et al., 2011 \& Cooper, 2005), These findings reflect the 
need of women to appreciate their husbands during this painful event, and the presence of husband will increase the bonds between him, his baby, and his wife.

As regards item of prepares the husband to accept his paternal responsibility, high score was obtained for this item. This result was in agreement with a study about Fathers' experience of childbirth, by (Vehviläinen-Julkunen \& Liukkonen, 1998), they reported that a significant moment for the acceptance of fatherhood for the husband, the moment he actually becomes a father. A quantitative Turkish study comparing 25 women with their partners present in childbirth, to 25 women who did not have their partners present revealed that women whose partners were present reported more positive birth experiences in all aspects of childbirth (Gungor $\boldsymbol{\&}$ Beji, 2007). In other two studies (Kainz et al., 2010 and Bondas-Salonen, 1998), Reported that, partner's presence helped women felt more control over their situation, felt safe and protected.

Participants of the present study were generally neutral to the idea of anxiety being transferred from the mother to her partner and psychological disturbance occurring in the husband, but they were slightly concerned that husbands might not cope with a complicated delivery. This finding was in agreement with the study of El-Maghrabi, \& Mohamed, (2012), who found that women in their study claimed that it may lead to psychological disorders in the husband. Also, Nejad, (2005), found in his study that participants were generally neutral to the idea of anxiety being transferred from the mother to her partner and psychological disturbance occurring in the husband, but they were slightly concerned that husbands might not cope with a complicated

delivery. Somers-Smith, (1999), showed that a prolonged and stressful labor could disturb the partner.

Since in Egypt has no tradition of the husband's presence in the delivery

room, also presence of husband is not a routine. Egyptian has little experience of the practice. Findings of current study suggest that providing facilities for the husband's presence in the delivery room is necessary. Also, couples should be trained for the husband's attendance in the delivery room during pregnancy

\section{Conclusion}

This study concluded that the majority of couples have had a positive attitude toward presence of husband during childbirth with significance difference. The majority of couples believed that attendance of husband during childbirth provide mother with emotional support, Increases the husband's sympathy and gratitude towards his wife, and strengthens the couple's relationship.

\section{Recommendations}

- Highlight the importance and activate the husband's involvement on maternal emotional well-being during childbirth.

- Health facilities, physicians and nurses should allow and encourage husband to attend child birth.

- Further research about the husband's presence and its effect on perinatal outcomes is highly recommended.

\section{References}

1. Abusha A., (2014): Assessment of male partners' involvement in promoting skilled delivery attendance of spouses and associated factors in lemo woreda, hadiya zone, southern nation nationality people. Thesis paper Submitted to the School of Graduate Studies of Addis Ababa University, College of Health Science Department of Nursing and Midwifery in Partial fulfillment of the requirements for the Degree of Master's of Science in Maternity Nursing and Reproductive Health

2. Adeniran A., Aboyeji A., Fawole A., Balogun O., Kikelomo T., Adesina K., \& Adeniran P., (2015): Male Partner's Role during Pregnancy, Labour and Delivery: Expectations of Pregnant women in Nigeria. International Journal of Health Sciences, Qassim University, Vol. 9, No. 3 (July-Sept 2015)

3. Bakhta Y., \& Lee R., (2010): A survey of Russian women regarding the presence of a companion during labor. International Journal of Gynecology \& Obstetrics, 109, 2, pp 201-203

4. Blackshaw, T., (2009): Fathers and childbirth. In C. Squire (Ed.). The Social Context of Birth. United Kingdom: Radcliffe Publishing Ltd.

5. Bondas-Salonen, T., (1998): How women experience the presence of their partners at the births of their babies. Qualitative Health Research, 8(6), 784-800. doi: 10.1177/104973239800800605

6. Cooper, S., (2005): A rite of involvement?: Men's transition to fatherhood. Durham Anthropology Journal, 13(2), 1-24.

7. El-Magrabi N., \& Mohamed N., (2012): Woman's Attitude towards the Presence of the Husband's in the Labor Room during Childbirth. Life Sci J 2012;9(4):3615-3620]. (ISSN: 10978135). 
8. Furuta M., Salway S., (2006): Women's position within the household as a determinant of maternal health care use in Nepal. Int Fam Plan Perspect. ; 32:17-27.

9. Gungor, I., \& Beji, K., (2007): Effects of fathers' attendance to labour and delivery on the experience of childbirth in Turkey. Western Journal of Nursing Research, 29(2), 213- 231. Doi: 10.1177/0193945906292538

10. Heather L., Longworth H., \& Kingdon C., (2011): Fathers in the birth room: What are they expecting and experiencing? A phenomenological study. Midwifery, vol. 7, Issue 5, pp 588-594

11. Hodnett, E., Gates, S., Hofmeyr, G., Sakala, C., \& Weston, J., (2011): Continuous support for women during childbirth (Review). The Cochrane Collaboration, 2, 1- 100.

12. Kainz, G., Eliasson, M., \& von Post, I., (2010): The child's father, an important person for the mother's wellbeing during the childbirth: A hermeneutic study. Health Care for Women International, 31, 621-635. doi: 10.1080/07399331003725499.

13. Kwambai T., Dellicour S., Desai M., Ameh C., Person B., Achieng F.,Mason L., Laserson K., \& Kuile F., (2013): Perspectives of men on antenatal and delivery care service utilisation in rural western Kenya: a qualitative study. BMC Pregnancy and Childbirth BMC series open, inclusive and trusted13:134

14. Larkin P., Begley C., Devane D., (2009): Women's experience of labour and birth: an evolutionary concept analysis. Midwifery, 25: 49-59.

15. Lewis S., Lee A., \& Simkhada P., (2015): The role of husbands in maternal health and safe childbirth in rural Nepal: a qualitative study. BMC Pregnancy and Childbirth ; 15:162. DOI 10.1186/s12884-015-0599-8.

16. Mullany B., Becker S, Hindin M., (2007): The impact of including husbands in antenatal health education services on maternal health practices in urban Nepal: results from a randomised controlled trial. Health Educ Res.; 22:166-76.

17. Nejad M., (2005): Couples' attitudes to the husband's presence in the delivery room during childbirth. Eastern Mediterranean Health Journal, Vol. 11, No. 4.

18. Pestvenidze, E., \& Bohrer, M., (2007): Finally, daddies in the delivery room: Parents' education in Georgia. Global Public Health, 2(2), 169-183. doi: 10.1080/17447690601054330

19. Plantin, L., Olukoya, A., \& Ny, P., (2011): Positive health outcomes of fathers' involvement in pregnancy and childbirth paternal support: A scope study literature review. Fathering, 9(1), 87-102. doi: 10.3149/fth.0901.87

20. Price, S., Noseworthy, J., \& Thornton, J. (2007): Women's experience with social presence during childbirth. The American Journal of Maternal/Child Nursing, 32(3), 184191.

21. Sapkota S., Kobayashi T, Kakehashi M, Baral G \& Yoshida I (2012): In the Nepalese context, can a husband's attendance during childbirth help his wife feel more in control of labour? BMC Pregnancy and ChildbirthBMC series. open, inclusive and trusted201212:49. DOI: 10.1186/1471-2393-1249

22. Sapkota, S., Kobayashi, T., \& Takase, M., (2011): Women's experience of giving birth with their husband's support in Nepal. British Journal of Midwifery, 19(7), 426-432.

23. Shahshahan Z., Mehrabian,F., Mashoori S., (2014): Effect of the presence of support person and routine intervention for women during childbirth in Isfahan, Iran: A randomized controlled trial. Adv Biomed Res, 3:155

24. Somers-Smith, M., (1999): A place for the partner? Expectations and experiences of support during childbirth. Midwifery, 15, 101-108.

25. Staessen, J., (2005): Social and professional support in childbirth. Retrieved August, 2013, from Armenian Medical Website: http://www.health.am/ab/more/social_and_profe ssional_support_in_childbirth/\#ixzz2 X8rBySrz

26. Theuring S., Mbezi P., Luvanda H., JordanHarder B., Kunz A., Harms G., (2009): Male involvement in PMTCT services in Mbeya Region, Tanzania. AIDS Behav. 2009, 13 (Suppl 1): 92-102.View ArticlePubMed

27. Vehviläinen-Julkunen, K., \& Liukkonen, A., (1998). Fathers' experience of childbirth. Midwifery, 14, 10-17. 